\title{
Kinetic Parameters for High Density Lipoprotein Apoprotein Al and Cholesteryl Ester Transport in the Hamster
}

\author{
Laura A. Woollett and David K. Spady \\ Department of Internal Medicine, The University of Texas Southwestern Medical Center at Dallas, Dallas, Texas 75235
}

\begin{abstract}
These studies were undertaken to determine the kinetic characteristics of high density lipoprotein (HDL) apo AI and cholesteryl ester transport in the hamster in vivo. Saturable HDL apo AI transport was demonstrated in the kidneys, adrenal glands, and liver. Saturable HDL cholesteryl ester transport was highest in the adrenal glands and liver. In the liver and adrenal glands, maximal transport rates $\left(J^{m}\right)$ for receptor dependent uptake were similar for the protein and cholesteryl ester moieties; however, the concentration of HDL necessary to achieve half-maximal transport $\left(K_{\mathrm{m}}\right)$ was 20- to 30-fold higher for apo AI. Consequently, at normal plasma HDL concentrations, the clearance of HDL cholesteryl ester exceeded that of HDL apo AI by $\sim 10$-fold in the adrenal glands and by approximately fivefold in the liver. At normal HDL concentrations, the majority of HDL cholesteryl ester $(76 \%)$ was cleared by the liver whereas the majority of HDL apo AI (77\%) was cleared by extrahepatic tissues. The rate of HDL cholesteryl ester uptake by the liver equaled the rate of cholesterol acquisition by all extrahepatic tissues suggesting that HDL cholesteryl ester uptake by the liver accurately reflects the rate of "reverse cholesterol transport." Receptor dependent HDL cholesteryl ester uptake by the liver was maximal (saturated) at normal plasma HDL concentrations. Consequently, changes in plasma HDL concentrations are not accompanied by parallel changes in the delivery of HDL cholesteryl ester to the liver unless the number or affinity of transporters is also regulated. $(J$. Clin. Invest. 1997. 99:1704-1713.) Key words: HDL • apoprotein $\mathrm{AI} \cdot$ cholesteryl ester transport • reverse cholesterol transport
\end{abstract}

\section{Introduction}

Epidemiological and clinical studies have demonstrated an inverse relationship between the concentration of high density lipoprotein (HDL) $)^{1}$-cholesterol in plasma and the risk of coronary heart disease (1-3). The protective role of HDL is usually

Address correspondence to David K. Spady, Department of Internal Medicine, UT Southwestern Medical Center, 5323 Harry Hines Blvd., Dallas, TX 75235-8887. Phone: 214-648-4545; FAX: 214-6489761; E-mail: spady@utsw.swmed.edu

Received for publication 6 August 1996 and accepted in revised form 22 January 1997.

J. Clin. Invest.

(C) The American Society for Clinical Investigation, Inc. 0021-9738/97/04/1704/10 \$2.00

Volume 99, Number 7, April 1997, 1704-1713 attributed to its ability to transport excess cholesterol from peripheral tissues back to the liver. Cholesterol that is synthesized or acquired from lipoproteins by extrahepatic tissues must be returned to the liver for excretion in a process that has been termed "reverse cholesterol transport" (4, 5). HDL clearly plays a major role in this process although many of the details still need to be clarified. In peripheral tissues, reverse cholesterol transport is initiated by the transfer of unesterified cholesterol from cell membranes to nascent HDL (5-7). In the presence of apo AI, lecithin cholesterol acyltransferase (LCAT) catalyzes the conversion of lecithin and cholesterol to lysolecithin and cholesteryl ester, which is followed by the partitioning of the hydrophobic cholesteryl ester moiety into the core of the HDL particle.

The return of HDL cholesterol to the liver may follow one of several routes. In the presence of cholesteryl ester transfer protein (CETP), a portion of the HDL cholesteryl ester is transferred to triglyceride-rich lipoproteins (in exchange for triglyceride) and ultimately returned to the liver via the low density lipoprotein (LDL) receptor and LDL receptor-related protein pathways (8). In addition, a portion of HDL is cleared from plasma and taken up by the liver as intact HDL particles (9, 10). Finally, HDL cholesteryl esters are delivered to the liver via a nonendocytic process in which cholesteryl ester is selectively taken up by the liver resulting in an HDL particle of reduced size and cholesteryl ester content $(11,12)$. This process may be mediated by the scavenger receptor type B1 (SR$\mathrm{BI}$ ), which was recently shown to mediate selective cholesteryl ester uptake when transfected into Chinese hamster ovary (CHO) cells (13). However, the exact role of this receptor in the selective uptake of HDL cholesteryl ester in vivo has yet to be determined.

To the extent that HDL clearance is mediated by receptor dependent processes, turnover will be saturable and tissue uptake will be dependent on the kinetic characteristics of the receptor dependent and receptor independent transport processes in each organ as well as on the number of transporters and the affinity with which HDL interacts with those transporters. Consequently, the mechanisms that regulate plasma HDL concentrations can only be understood if information is available regarding the relationship between plasma HDL concentrations and rates of HDL transport in normal animals.

The present studies were undertaken to establish the kinetics of HDL apo AI and cholesteryl ester transport in the ham-

1. Abbreviations used in this paper: CETP, cholesteryl ester transfer protein; $\mathrm{CHO}$, Chinese hamster ovary; HDL, high density lipoprotein(s); $J^{\mathrm{m}}$, maximal rate of receptor dependent transport; $K_{\mathrm{m}}$, concentration necessary to achieve half maximal transport via receptor dependent pathways; LDL, low density lipoprotein(s); P, proportionality constant for receptor independent uptake; SR-BI, scavenger receptor type B1. 
ster in vivo. While the hamster has become a well-established model for the study of cholesterol, bile acid, and LDL metabolism, there is relatively little information on HDL transport. The hamster appears to be an excellent model for the study of HDL metabolism and reverse cholesterol transport. Serum HDL levels respond to dietary factors in a similar manner in hamsters $(14,15$, and L.A. Woollett and D.K. Spady, unpublished observations) and humans $(3,16,17)$. Hamsters do not develop large amounts of apo E-rich particles in the HDL density range in response to cholesterol feeding (14, and L.A. Woollett and D.K. Spady, unpublished observations). Most importantly, it is possible to quantify rates of cholesterol acquisition in all of the peripheral tissues of the body, which in a steady state, equals the rate of movement of cholesterol from peripheral tissues back to the liver (reverse cholesterol transport).

\section{Methods}

Animals and diets. Male Golden Syrian hamsters (Sasco, Inc., Omaha, $\mathrm{NE}$ ) were housed in colony cages (5-6 animals/cage) and subjected to alternating 12-h periods of light and darkness. During this time, animals were maintained on a standard cereal-based (low fat, low cholesterol) rodent diet (Teklad Premier Laboratory Diets, Madison, WI). Animals were in the weight range of $130-160 \mathrm{~g}$ at the time specific experiments were performed. All studies were carried out during the mid-dark phase of the light cycle. All experiments were approved by the Institutional Animal Care and Research Advisory Committee of the University of Texas Southwestern Medical Center at Dallas.

Determination of HDL Apo AI transport. HDL apo AI transport was quantified in vivo using a primed-continuous infusion of radiolabeled HDL apo AI (18). Plasma was obtained from normocholesterolemic hamsters maintained on a standard cereal-based rodent diet, and HDL was isolated in the density range of $1.07-1.21 \mathrm{~g} / \mathrm{ml}$ using sequential preparative ultracentrifugation and standard techniques (19). Hamster HDL in this density range contains almost exclusively apo AI (20) as confirmed on overloaded SDS polyacrylamide gels (not shown). HDL apo AI was labeled in situ with the intracellularly trapped marker $\left[{ }^{125} \mathrm{I}\right]$ tyramine cellobiose (21) or with ${ }^{131} \mathrm{I}$ (22). The molar ratio of tyramine cellobiose to apo AI was $\sim 0.06$ and the final specific activity of the radiolabeled HDL preparations was $\sim 200 \mathrm{dpm} / \mathrm{ng}$ protein. Greater than $96 \%$ of the $\left[{ }^{125} \mathrm{I}\right]$ tyramine cellobiose label was precipitable with trichloroacetic acid and $\leq 4 \%$ was extractable into $2: 1$ chloroform/methanol. The final specific activity for the ${ }^{131}$ I-labeled HDL was $\sim 3,000 \mathrm{dpm} / \mathrm{ng}$ protein. Preliminary studies showed that the tissue spaces for HDL at 10 min were identical whether HDL was labeled with $\left[{ }^{125} \mathrm{I}\right]$ tyramine cellobiose or ${ }^{131} \mathrm{I}$.

Animals were administered a priming dose of [ $\left.{ }^{125} \mathrm{I}\right]$ tyramine cellobiose-labeled HDL through a femoral vein catheter followed by a continuous infusion of the same radiolabeled lipoprotein so as to maintain a constant plasma specific activity. Femoral vein catheters were placed under brief $(\sim 3 \mathrm{~min})$ diethyl ether anesthesia. The period of time that elapsed between insertion of catheters and initiation of infusions varied from 10-30 min.

In some studies, infusions were continued for 1,2 , or $4 \mathrm{~h}$ to determine the time course of radiolabeled HDL apo AI uptake in the various tissues of the body. In most studies, primed infusions of $\left[{ }^{125} \mathrm{I}\right] \mathrm{ty}-$ ramine cellobiose-labeled HDL were continued for $4 \mathrm{~h}$ at which time the animals were administered ${ }^{131} \mathrm{I}$-labeled HDL intravenously (as a marker of the volume of plasma in each tissue) and killed $10 \mathrm{~min}$ later. Plasma and tissue samples were assayed for radioactivity in a gamma counter (Packard Instrument Co., Inc., Downers Grove, IL) to an accuracy of $\pm 2 \%$. The tissue spaces achieved by the labeled HDL at 10 min $\left({ }^{131}\right.$ I disintegrations per minute per gram of tissue divided by the ${ }^{131}$ I disintegrations per minute per microliter of plasma) and at $4 \mathrm{~h}$ and $10 \mathrm{~min}\left({ }^{125} \mathrm{I}\right.$ disintegrations per minute per gram of tis- sue divided by the steady state ${ }^{125}$ I disintegrations per minute per microliter of plasma) were then calculated and have the units of microliters per gram. The tissue space at $10 \mathrm{~min}$ represents radiolabeled HDL apo AI present within the plasma and interstitial spaces. The linear increase in tissue space between the 10-min time point and the 4-h and 10-min time point equals the rate of radiolabeled HDL apo AI movement into the intracellular space of each organ and is expressed as the microliters of plasma cleared of its HDL apo AI content per hour per gram of tissue or per whole organ (23). Clearance values were multiplied by the plasma HDL apo AI concentration to obtain the absolute rates of HDL apo AI uptake.

The lipoprotein distribution of labeled apo AI was determined by FPLC (Pharmacia Fine Chemicals, Uppsala, Sweden). At the completion of each study, equal volumes of plasma from animals within an experimental group were pooled and $3 \mathrm{ml}$ was injected onto a superose 6 (Sigma Chemical Co., St. Louis, MO) column as previously described (24). After a void volume of $45 \mathrm{ml}, 2-\mathrm{ml}$ fractions were collected and assayed for radioactivity in a gamma counter.

Unless otherwise specified, the primed infusions contained trace amounts of radiolabeled HDL apo AI that had no effect on plasma HDL apo AI concentrations. In some experiments, the kinetics of HDL apo AI transport were investigated using primed infusions of radiolabeled HDL apo AI to which mass amounts of unlabeled hamster HDL $(d=1.07-1.21 \mathrm{~g} / \mathrm{ml})$ had been added. Preliminary studies were performed to determine how much radiolabeled HDL apo AI needed to be infused each hour (relative to the priming dose) to maintain a constant specific activity of HDL apo AI in plasma. In the case of trace-labeled HDL apo AI, $6 \%$ of the priming dose was required per hour as a continuous infusion to maintain a constant plasma specific activity of radiolabeled HDL during the $4 \mathrm{~h}$ experimental period. When mass amounts of HDL were added to the trace-labeled HDL apo AI, the amount of radiolabeled HDL required per hour (relative to the priming dose) to maintain a constant plasma specific activity was reduced in proportion to the mass of HDL that was added to the primed infusion. In animals receiving the largest mass amounts of HDL ( $50 \mathrm{mg}$ of hamster HDL apo AI per $100 \mathrm{~g}$ body weight added to the primed infusion), only $3 \%$ of the priming dose was required per hour to maintain a constant plasma specific activity (and HDL apo AI concentration). In no case did the specific activity of plasma HDL apo AI or HDL apo AI mass differ by more than $4 \%$ between the 10 min time point and the $4 \mathrm{~h}$ and 10 min time point.

Determination of albumin transport. Tissue clearance rates for albumin were measured using primed infusions of [ $\left.{ }^{125} \mathrm{I}\right]$ tyramine cellobiose-labeled hamster albumin (using the same protocol described above for HDL apo AI). The molar ratio of tyramine cellobiose to albumin was 0.1 and the specific activity of the radiolabeled albumin preparation was $300 \mathrm{dpm} / \mathrm{ng}$ of protein. Greater than $96 \%$ of the radioactivity in the radiolabeled albumin preparation was precipitable with trichloroacetic acid. At the end of the 4-h infusions each animal was administered a bolus of ${ }^{131}$ I-labeled hamster albumin (as a measure of the volume of plasma within each tissue) and killed $10 \mathrm{~min}$ later. Based on the results of preliminary studies, the continuous infusions delivered $5 \%$ of the priming dose each hour to maintain the specific activity of albumin in plasma constant over the 4-h experimental period.

Determination of HDL cholesteryl ether transport. Hamster HDL $(d=1.07-1.21 \mathrm{~g} / \mathrm{ml})$ was isolated as described above and labeled with either the intracellularly trapped $\left[1 \alpha, 2 \alpha(\mathrm{n})-{ }^{3} \mathrm{H}\right]$ cholesteryl oleyl ether (25-27) or [cholesteryl-4- ${ }^{14} \mathrm{C}$ ]oleate by exchange from donor liposomes as described $(11,28)$. Freshly collected rabbit plasma or a $d>1.21 \mathrm{~g} / \mathrm{ml}$ fraction of rabbit plasma was used as a source of CETP (11). HDL labeled with either source of CETP gave identical tissue uptake rates. When fresh rabbit plasma was used as the source of CETP, rabbit HDL accounted for $\leq 5 \%$ of the HDL in the reaction mixture. The labeled HDL were reisolated by ultracentrifugation $(d=1.07-1.21 \mathrm{~g} / \mathrm{ml})$, dialyzed against saline and used within $24 \mathrm{~h}$. The specific activity of the radiolabeled HDL preparations ranged from $15-30 \mathrm{dpm} / \mathrm{ng}$ cholesteryl ester. 
Rates of HDL cholesteryl ether transport were determined using the primed infusion protocol described above for HDL apo AI. In some experiments, the infusions of $\left[{ }^{3} \mathrm{H}\right]$ cholesteryl ether-labeled HDL were continued for 1,2 , or $4 \mathrm{~h}$ to determine the time course of HDL cholesteryl ether transport. In most studies, primed infusions of $\left[{ }^{3} \mathrm{H}\right]$ cholesteryl ether-labeled HDL were continued for $4 \mathrm{~h}$ at which time the animals were administered $\left[{ }^{14} \mathrm{C}\right]$ cholesteryl ester-labeled HDL intravenously and killed $10 \mathrm{~min}$ later. Plasma and tissue samples were saponified in alcoholic $\mathrm{KOH}$ (29-31). After saponification, each of the samples was adjusted with water to contain $\sim 50 \%$ ethanol and the sterols quantitatively extracted using petroleum ether $(29,31)$. An exact aliquot of the petroleum ether extract was dried in a scintillation vial, scintillation solution was added, and the samples were assayed for their ${ }^{3} \mathrm{H}$ and ${ }^{14} \mathrm{C}$ content in a scintillation counter (Beckman Instruments Inc., Fullerton, CA) to an accuracy of $\pm 2 \%$. The lipoprotein distribution of ${ }^{3} \mathrm{H}$ and ${ }^{14} \mathrm{C}$ was determined by FPLC as described above for HDL apo AI. Unless otherwise specified, the primed infusions contained trace amounts of radiolabeled HDL cholesteryl ether that had no effect on plasma HDL cholesterol concentrations. In some experiments the relationship between HDL cholesteryl ester transport and the concentration of HDL cholesteryl ester in plasma was determined by adding mass amounts of unlabeled hamster HDL $(d=1.07-1.21 \mathrm{~g} / \mathrm{ml})$ to the primed infusions of labeled HDL.

Preliminary studies were performed to determine the amount of radiolabeled HDL cholesteryl ether required in the hourly infusions (relative to the priming dose) to maintain a constant level of HDL cholesteryl ether in plasma. In the case of trace-labeled HDL cholesteryl ether, $10 \%$ of the priming dose was required per hour as a continuous infusion to maintain the plasma concentration of radiolabeled HDL constant during the 4-h experimental period. When mass amounts of HDL were added to the trace-labeled HDL cholesteryl ether, the amount of radiolabeled HDL required per hour (relative to the priming dose) to maintain a constant plasma specific activity was reduced in proportion to the mass of HDL in the primed infusion. In animals receiving the largest mass amounts of HDL (30 mg HDL cholesteryl ester per $100 \mathrm{~g}$ body weight added to the primed infusion), only $3 \%$ of the priming dose was required per hour to maintain a constant plasma specific activity (and HDL cholesteryl ester concentration). In no case did the plasma concentration of HDL cholesteryl ether label (or HDL cholesteryl ester mass) differ by more than 5\% between the 10-min time point and the 4-h and 10-min time point.

Determination of tissue LDL cholesterol uptake rates. Rates of LDL cholesterol uptake were measured using primed infusions of [25I]tyramine cellobiose-labeled homologous LDL as described previously (15). The molar ratio of tyramine cellobiose to apo B was $\sim 1$ and the specific activity of the radiolabeled LDL preparations equaled $\sim 300 \mathrm{dpm} / \mathrm{ng}$ protein. Greater than $96 \%$ of the radioactivity in the labeled LDL preparation was precipitable with trichloroacetic acid and $<4 \%$ of the label was extractable into 2:1 chloroform/methanol. At the end of the $4 \mathrm{~h}$ infusions each animal was administered a bolus of ${ }^{131} \mathrm{I}$-labeled hamster LDL (as a measure of the volume of plasma within each tissue) and killed $10 \mathrm{~min}$ later. The final specific activity for the ${ }^{131} \mathrm{I}$-labeled LDL was $\sim 3,000 \mathrm{dpm} / \mathrm{ng}$ protein. Preliminary studies showed that the tissue spaces for LDL at $10 \mathrm{~min}$ were identical whether the LDL was labeled with $\left[{ }^{125} \mathrm{I}\right]$ tyramine cellobiose or ${ }^{131} \mathrm{I}$.

Determination of cholesterol synthesis rates. Hamsters were administered $\sim 100 \mathrm{mCi}$ of $\left[{ }^{3} \mathrm{H}\right]$ water intravenously $(29,30)$. One hour later the animals were anesthetized and exsanguinated through the abdominal aorta. Aliquots of plasma were taken for the determination of body water specific activity, and samples of liver and various extrahepatic tissues as well as the entire remaining carcass were taken for the isolation of digitonin-precipitable sterols (31). Tissues were saponified and the digitonin-precipitable sterols isolated and assayed for tritium content. Rates of sterol synthesis are expressed as the micrograms of sterol formed per hour assuming that $22{ }^{3} \mathrm{H}$ are incorporated into cholesterol in the presence of $\left[{ }^{3} \mathrm{H}\right]$ water in vivo, as previously demonstrated for the hamster $(29,30)$.
Determination of plasma cholesterol and apo AI distribution. The cholesterol distribution among plasma lipoproteins was determined by FPLC using a superose 6 column. $2-\mathrm{ml}$ fractions were collected and assayed for cholesterol and apo AI. Cholesterol was assayed using an enzymatic kit (Sigma Chemical Co., catalogue No. 352). Apo AI was assayed using a turbidometric assay essentially as described (32). The apo AI antisera was prepared in rabbits using apo AI purified from delipidated hamster HDL $(d=1.07-1.21 \mathrm{~g} / \mathrm{ml})$ by anion exchange (Mono Q, Pharmacia LKB Biotechnology, Inc., Piscataway, $\mathrm{NJ}$ ) and gel filtration (superose 12) chromatography as described (33).

Calculations and statistical analysis. Rates of HDL apo AI and cholesteryl ester transport were quantified in normal animals under conditions in which circulating HDL concentrations were acutely raised and maintained at various levels during the $4 \mathrm{~h}$ experimental period as described above. Values for tissue HDL apo AI or cholesteryl ester uptake were plotted as a function of the concentration of HDL apo AI or cholesteryl ester in the same animal. The kinetic parameters for HDL apo AI and cholesteryl ester transport were determined by fitting these data to an equation that takes into account both receptor dependent (saturable) and receptor independent (nonsaturable) transport.

The rate of HDL apo AI or cholesteryl ester uptake by a particular tissue $\left(J_{t}\right)$ is equal to the sum of the rates of uptake via receptor dependent and receptor independent transport processes. Receptor dependent transport can be described by the equation $J^{\mathrm{m} *} \mathrm{C} /\left(K_{\mathrm{m}}+\mathrm{C}\right)$, where $J^{\mathrm{m}}$ equals the maximal rate of tissue HDL apo AI or cholesteryl ester uptake, $K_{\mathrm{m}}$ equals the concentration of HDL apo AI or cholesteryl ester in plasma necessary to achieve half-maximal rates of tissue uptake and $\mathrm{C}$ equals the concentration of HDL apo AI or cholesteryl ester in plasma. Receptor independent transport equals $\mathrm{P} * \mathrm{C}$, where $\mathrm{P}$ equals the proportionality constant for receptor independent uptake. Values for tissue HDL apo AI or cholesteryl ester uptake were plotted as a function of the concentration of HDL apo AI or cholesteryl ester in the same animal and these data were fitted to the

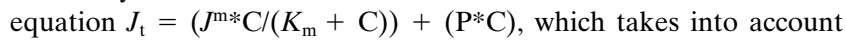
both receptor dependent and receptor independent transport, using the software package Ultrafit (Biosoft, Cambridge, UK). The three parameter values $\left(J^{\mathrm{m}}, K_{\mathrm{m}}\right.$, and $\mathrm{P} \pm 95 \%$ confidence intervals) were calculated using the Marquardt algorithm for nonlinear regression and proportional weighting (34). All other data are presented as means \pm 1 SD.

\section{Results}

Tissue distribution and kinetics of HDL apo AI transport. Rates of HDL apo AI transport were quantified using primed infusions of homologous HDL. HDL apo AI was labeled with the nondegradable, intracellularly trapped tracer $\left.{ }^{[25} \mathrm{I}\right]$ tyramine cellobiose. The metabolic behavior of HDL apo AI differs somewhat depending on whether apo AI has been labeled in situ or by an in vitro transfer procedure, with the in situ labeled HDL apparently tracing normal HDL apo AI turnover more accurately (35). In the current studies, hamster HDL apo AI was labeled with $\left[{ }^{125} \mathrm{I}\right]$ tyramine cellobiose in situ. Tyramine cellobiose apparently did not alter the metabolic behavior of HDL apo AI in that plasma clearance rates for hamster HDL labeled with $\left[{ }^{125} \mathrm{I}\right]$ tyramine cellobiose or ${ }^{131}$ I were identical (not shown). Under conditions in which the specific activity of HDL apo AI was maintained at a constant level in plasma, radiolabel accumulated in every organ of the body as a linear function of time for at least $4 \mathrm{~h}$ (between $10 \mathrm{~min}$ and $4 \mathrm{~h}$ and 10 min) as illustrated in Fig. 1 for the adrenal glands, liver, and kidneys. At the completion of the studies, the lipoprotein distribution of radiolabeled apo AI was determined by FPLC. No 


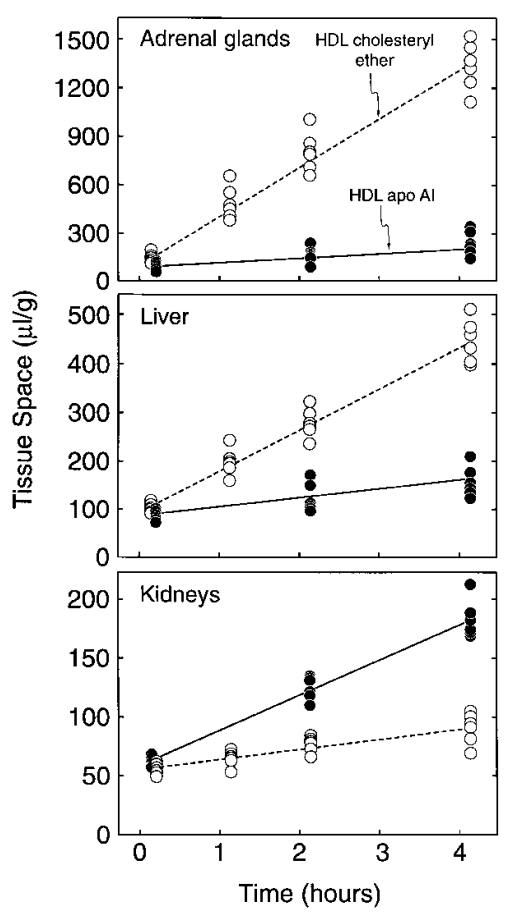

Figure 1. Tissue accumulation of HDL apo $\mathrm{AI}$ and cholesteryl ether as a function of time in animals administered primed infusions of trace labeled HDL apo AI or HDL cholesteryl ether as described in Methods. The amount of radiolabeled HDL apo AI or cholesteryl ether present in a tissue is expressed in terms of the plasma volume that would contain the same amount of radiolabeled HDL ( Tissue Space). The increase in tissue space with time equals the clearance rate in microliters of plasma cleared entirely of HDL apo AI or cholesteryl ether per hour per gram of tissue. Each point represents the value from an individual animal.

radioactivity was detected in fractions other than those corresponding to authentic hamster HDL $(d=1.07-1.21 \mathrm{~g} / \mathrm{ml})$.

Using the $4 \mathrm{~h}$ experimental protocol described in Methods, the tissue distribution of HDL apo AI transport was determined in animals with normal HDL concentrations and the results are shown in Fig. 2. When expressed per gram tissue (top), the kidneys exhibited the highest rate of HDL apo AI clearance followed by adrenal glands and liver. When expressed per whole organ (bottom), the liver was the single most important site of apo AI uptake but accounted for only $\sim 23 \%$ of total apo AI turnover. It should be emphasized, however, that the clearance values shown in Fig. 2 apply only to animals with normal plasma HDL concentrations. To the extent that apo AI is cleared by receptor dependent mechanisms in one or more organs of the body, the organ distribution of HDL apo AI clearance will vary with plasma HDL apo AI concentrations depending on the kinetics of the receptor dependent and receptor independent transport processes in each tissue.

The kinetics of HDL Apo AI transport were determined in normal animals using primed infusions of radiolabeled HDL apo AI containing varying mass amounts of unlabeled homologous HDL (0-50 mg HDL apo AI per $100 \mathrm{~g}$ body weight). Fig. 3 shows rates of HDL apo AI clearance by the kidneys, adrenal glands, and liver as a function of the concentration of HDL apo AI that was maintained in plasma during the $4 \mathrm{~h}$ experimental period. In these organs, the rate of apo AI clearance decreased as a function of the concentration of HDL in plasma. At the highest HDL apo AI concentrations achieved in these studies, $(\sim 1,200 \mathrm{mg} / \mathrm{dl})$, clearance rates for HDL apo AI approached those of serum albumin. The product of the HDL apo AI clearance rate and the plasma HDL apo AI concentration equals the absolute rate of HDL apo AI uptake.

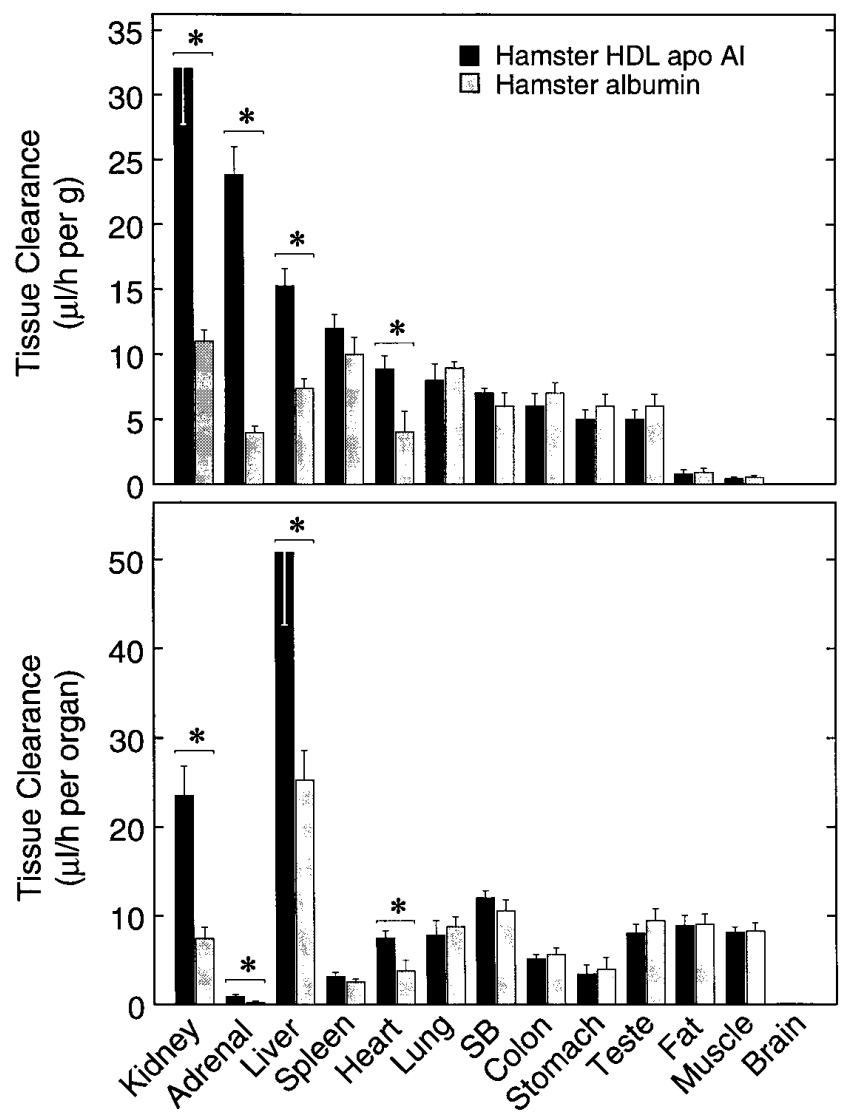

Figure 2. Rates of tissue HDL apo AI and serum albumin clearance by individual organs of the hamster. Tissue clearance rates were determined in vivo using primed infusions of trace labeled HDL apo AI or albumin as described in Methods. Tissue clearance rates are expressed as the microliters of plasma cleared of HDL apo AI or albumin per hour per gram of tissue (top) or per whole organ per $100 \mathrm{~g}$ body weight (bottom). The data represent the mean \pm 1 SD for data obtained in 12 (HDL apo AI) or 6 (albumin) animals. *Indicates a significant difference $(P<0.05)$ between the clearance rates for HDL apo AI and serum albumin.

Fig. 4 shows the rates of HDL apo AI uptake by the kidneys, adrenal glands, and liver as a function of the concentration of HDL apo AI that was maintained in plasma during the $4 \mathrm{~h}$ experimental period. In these tissues, rates of apo AI uptake increased as a curvilinear function of plasma HDL apo AI concentrations indicating competition for a limited number of transport sites. Rates of apo AI uptake in the remaining tissues of the body were low (when expressed per gram of tissue) and increased as a linear function of plasma HDL apo AI concentrations.

Tissue distribution and kinetics of HDL cholesteryl ester transport. HDL cholesteryl ester transport was traced with homologous HDL particles labeled with $\left[{ }^{3} \mathrm{H}\right]$ cholesteryl oleyl ether, a nondegradable marker that remains intracellularly trapped following uptake. Using the 4-h experimental protocol described in Methods, the tissue distribution of HDL cholesteryl ether transport was determined in animals with normal HDL concentrations and the results are shown in Fig. 5 (HDL apo AI clearance rates are also shown for comparative purposes). When expressed per gram of tissue (top), the highest 


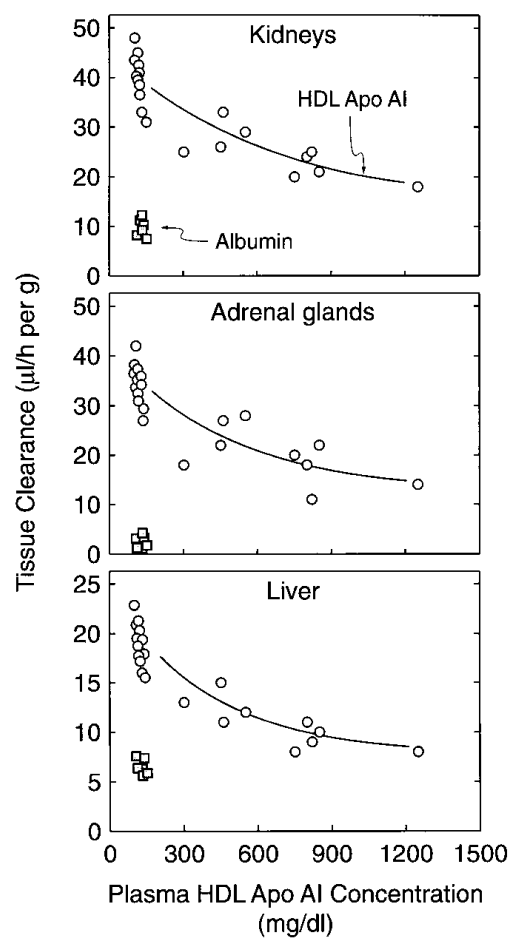

rates of HDL cholesteryl ether clearance were in the adrenal glands $(288 \mu \mathrm{l} / \mathrm{h}$ per $\mathrm{g})$ and liver $(82 \mu \mathrm{l} / \mathrm{h}$ per $\mathrm{g})$. When expressed per whole organ (bottom), the liver was the most important site of HDL cholesteryl ether transport accounting for $\sim 76 \%$ of total HDL cholesteryl ether turnover in control hamsters. The clearance of HDL cholesteryl ether exceeded that of HDL apo AI by $~ 10$-fold in the adrenal glands and by approximately fivefold in the liver. As shown in Fig. 6, very lit-

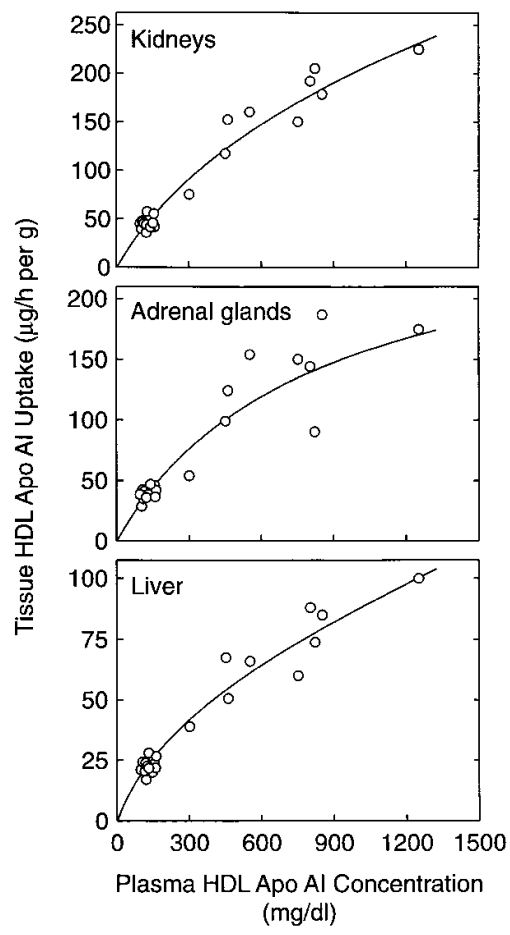

Figure 4. Rates of HDL apo AI uptake by the kidneys, adrenal glands, and liver as a function of the concentration of HDL apo AI in plasma. Each of the clearance rates shown in Fig. 3 was multiplied by the steady state plasma HDL apo AI concentration in the same animal to yield the absolute rates of HDL apo AI uptake (expressed as the micrograms of HDL apo AI taken up per hour per gram of tissue).
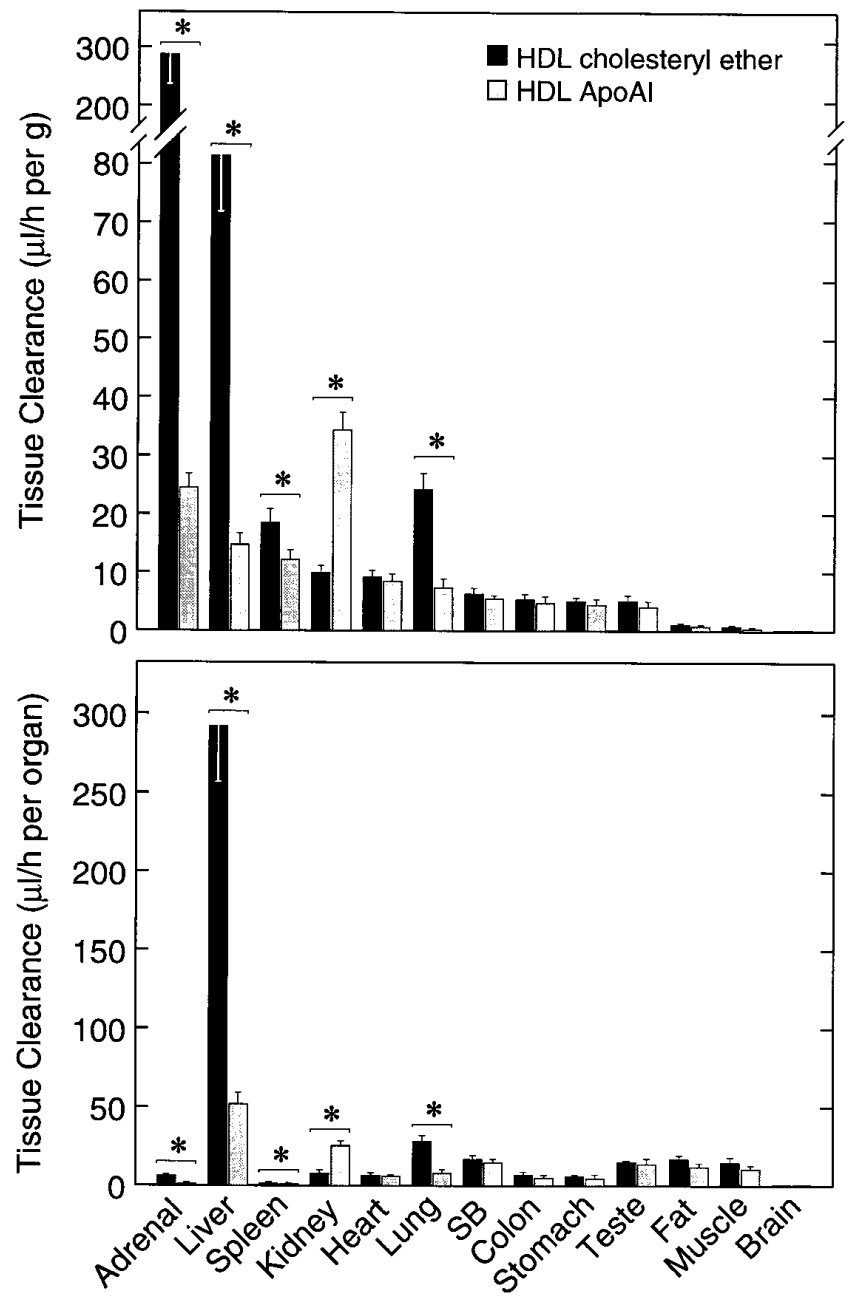

Figure 5. Rates of tissue HDL cholesteryl ether and apo AI uptake by individual organs of the hamster. Tissue clearance rates were determined in vivo using primed infusions of trace labeled HDL cholesteryl ether or apo AI as described in Methods and are expressed as the microliters of plasma cleared of HDL cholesteryl ether or apo AI per hour per gram of tissue (top) or per whole organ per $100 \mathrm{~g}$ body weight (bottom). The data represent the mean $\pm 1 \mathrm{SD}$ for data obtained in 12 animals per group. *Indicates a significant difference $(P<0.05)$ between the clearance rates for HDL cholesteryl ether and apo AI.

tle HDL cholesteryl ether accumulated in the lower density lipoprotein fractions during the $4 \mathrm{~h}$ experimental time period, consistent with the known low level of CETP in this species $(20,36)$ and the somewhat reduced activity of CETP for ether (relative to ester) conjugates of cholesterol (37).

The kinetics of HDL cholesteryl ester transport were examined using primed infusions of radiolabeled HDL cholesteryl ether containing varying mass amounts of unlabeled homologous HDL (0-30 mg HDL cholesteryl ester per $100 \mathrm{~g}$ body weight). Fig. 7 shows HDL cholesteryl ether clearance rates in the adrenal glands, liver, and spleen as a function of the concentration of HDL cholesteryl ester in plasma during the 4-h experimental period. Hepatic cholesteryl ether clearance declined steeply as a function of plasma HDL cholesteryl ester concentrations such that HDL cholesteryl ether clear- 


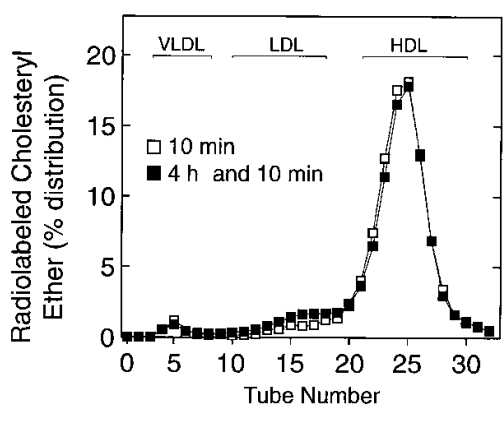
and separated by superose 6 chromatography as described in Methods. $2-\mathrm{ml}$ fractions were collected and assayed for radioactivity. The retention times for hamster VLDL $(d<1.006 \mathrm{~g} / \mathrm{ml})$, LDL $(d=1.02-1.055$ $\mathrm{g} / \mathrm{ml})$, and HDL $(d=1.07-1.21 \mathrm{~g} / \mathrm{ml})$ are indicated. The data represent the mean of two such experiments.

ance was reduced by $\sim 50 \%$ under conditions in which circulating HDL cholesteryl ester levels were increased approximately twofold. As a consequence, the absolute rate of HDL cholesteryl ester uptake by the liver was maximal (saturated) at normal plasma HDL concentrations and remained essentially constant at higher plasma HDL levels as shown in Fig. 8.

Kinetic parameters for HDL apo AI and cholesteryl ester transport. Using curve fitting software and a regression equation that takes into account the kinetics of both receptor dependent and receptor independent transport, the data illustrated in Figs. 4 and 8 were subjected to nonlinear regression analysis as described in Methods. The kinetic parameters for receptor dependent $\left(J^{\mathrm{m}}\right.$ and $\left.K_{\mathrm{m}}\right)$ and receptor independent $(\mathrm{P})$

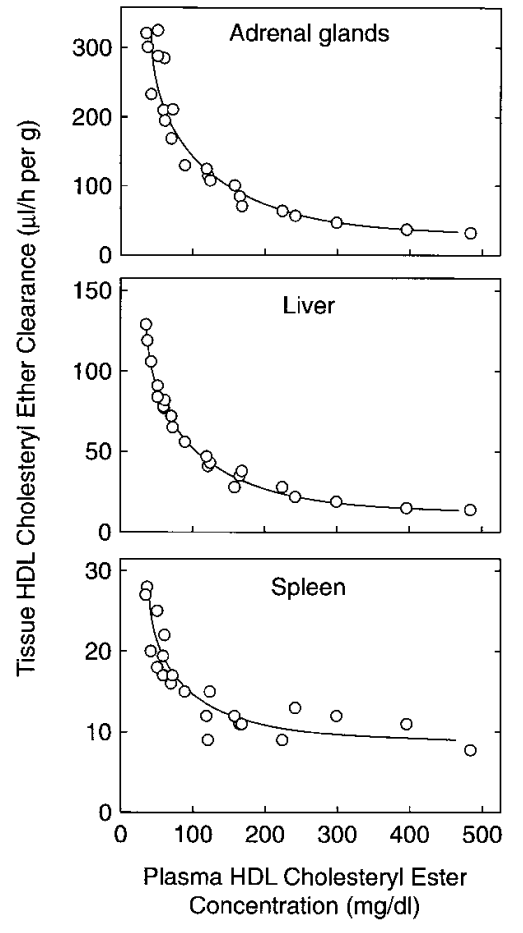

Figure 7. Rates of HDL cholesteryl ether clearance by the adrenal glands, liver, and spleen as a function of the concentration of HDL cholesteryl ester in plasma. Rates of HDL cholesteryl ether clearance were quantified in vivo using primed infusions of trace labeled HDL. In some animals mass amounts of homologous HDL were added to the primed infusions of trace labeled HDL to abruptly achieve new steady state concentrations of plasma HDL cholesteryl ester (ranging from 89 to $486 \mathrm{mg} /$ dl). Each point represents the value for an individual animal.

transport that were generated by this analysis are shown in Table I. Saturable receptor dependent HDL apo AI uptake could be demonstrated in the kidneys, adrenal glands and liver with values for $J^{\mathrm{m}}$ (maximal uptake rate) of 207, 135, and $56 \mu \mathrm{g} / \mathrm{h}$ per gram, respectively. Values for $K_{\mathrm{m}}$ (the concentration of

Table I. Transport Parameters for Receptor Dependent and Receptor Independent HDL apo AI and Cholesteryl Ester Uptake

\begin{tabular}{|c|c|c|c|c|c|c|}
\hline \multirow[b]{3}{*}{ Tissue } & \multicolumn{3}{|c|}{ HDL apo AI parameters } & \multicolumn{3}{|c|}{ HDL cholesteryl ester parameters } \\
\hline & \multicolumn{2}{|c|}{ Receptor dependent } & \multirow{2}{*}{$\begin{array}{c}\begin{array}{c}\text { Receptor } \\
\text { independent }\end{array} \\
\mathrm{P}\end{array}$} & \multicolumn{2}{|c|}{ Receptor dependent } & \multirow{2}{*}{$\begin{array}{c}\begin{array}{c}\text { Receptor } \\
\text { independent }\end{array} \\
\mathrm{P}\end{array}$} \\
\hline & $J^{\mathrm{m}}$ & $K_{\mathrm{m}}$ & & $J^{\mathrm{m}}$ & $K_{\mathrm{m}}$ & \\
\hline & $\mu g / h$ per $g$ & $m g / d l$ & $\mu g / h$ per $g$ per $m g / d l$ & $\mu g / h$ per $g$ & $m g / d l$ & $\mu g / h$ per $g$ per $m g / d l$ \\
\hline Liver & $56 \pm 36$ & $277 \pm 176$ & $0.04 \pm 0.04$ & $58 \pm 10$ & $14 \pm 10$ & $0.03 \pm 0.01$ \\
\hline Adrenal glands & $135 \pm 89$ & $372 \pm 168$ & $0.04 \pm 0.05$ & $147 \pm 43$ & $11 \pm 13$ & $0.03 \pm 0.01$ \\
\hline Kidneys & $207 \pm 88$ & $434 \pm 288$ & $0.07 \pm 0.06$ & $4 \pm 3$ & $5 \pm 29$ & $0.02 \pm 0.01$ \\
\hline Spleen & ND* & ND & $0.07 \pm 0.03$ & $9 \pm 1$ & $17 \pm 33$ & $0.05 \pm 0.02$ \\
\hline Lungs & ND & ND & $0.05 \pm 0.02$ & $17 \pm 9$ & $14 \pm 39$ & $0.05 \pm 0.05$ \\
\hline Heart & ND & ND & $0.06 \pm 0.03$ & $5 \pm 6$ & $16 \pm 22$ & $0.04 \pm 0.04$ \\
\hline Small bowel & ND & ND & $0.06 \pm 0.04$ & $4 \pm 4$ & $17 \pm 27$ & $0.03 \pm 0.03$ \\
\hline Colon & ND & ND & $0.04 \pm 0.03$ & $3 \pm 4$ & $18 \pm 35$ & $0.02 \pm 0.04$ \\
\hline Stomach & ND & ND & $0.03 \pm 0.03$ & $2 \pm 2$ & $12 \pm 18$ & $0.02 \pm 0.03$ \\
\hline Testes & ND & ND & $0.04 \pm 0.02$ & $2 \pm 3$ & $15 \pm 27$ & $0.03 \pm 0.02$ \\
\hline Fat & ND & ND & $0.02 \pm 0.02$ & $1 \pm 3$ & $19 \pm 25$ & $0.01 \pm 0.02$ \\
\hline Skeletal muscle & ND & ND & $<0.01$ & ND & ND & $<0.01$ \\
\hline Brain & ND & ND & $<0.01$ & ND & ND & $<0.01$ \\
\hline
\end{tabular}

Rates of HDL apo AI and cholesteryl ester transport were quantified in normal animals under conditions in which circulating HDL concentrations were acutely raised and maintained at various levels during the $4 \mathrm{~h}$ experimental period. Values for tissue HDL apo AI or cholesteryl ester uptake were plotted as a function of the concentration of HDL apo AI or cholesteryl ester in the same animal as shown for selected tissues in Figs. 4 and 8. The kinetic parameters for HDL apo AI and cholesteryl ester transport ( $\pm 95 \%$ confidence intervals) were calculated by fitting these data to an equation that takes into account both receptor dependent (saturable) and receptor independent (nonsaturable) transport as described in Methods. *Not detected. In these tissues, the receptor dependent component was so low that parameter values $\left(J^{\mathrm{m}}, K_{\mathrm{m}}\right)$ could not be determined. 


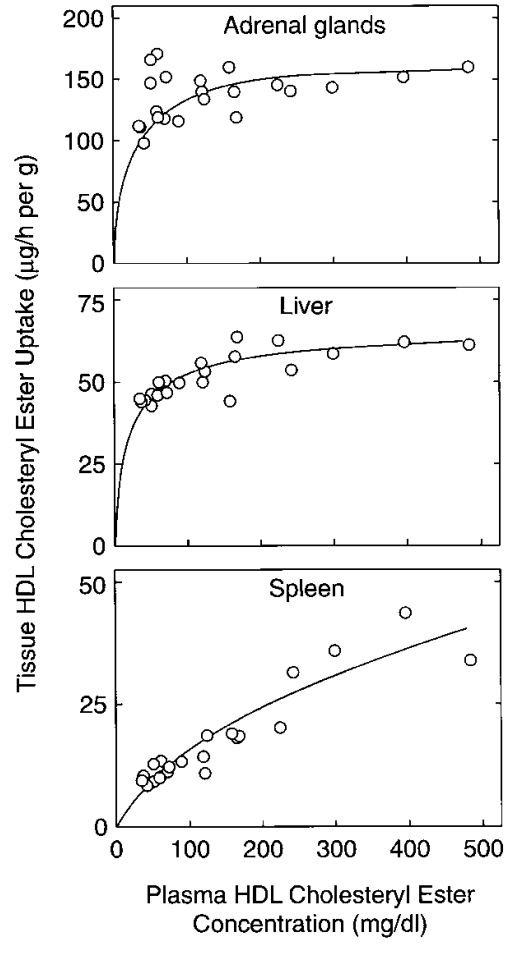

Figure 8. Rates of HDL cholesteryl ester uptake by the adrenal glands, liver, and spleen as a function of the concentration of HDL cholesteryl ester in plasma. Each of the clearance rates shown in Fig. 7 was multiplied by the steady state plasma HDL cholesteryl ester concentration in the same animal to yield the absolute rate of HDL cholesteryl ester uptake (expressed as the micrograms of HDL cholesteryl ester taken up per hour per gram of tissue).

HDL apo AI in plasma necessary to achieve half-maximal uptake) were quite high equaling 434, 372, and $277 \mathrm{mg} / \mathrm{dl}$ in the kidneys, adrenal glands, and liver, respectively. These $K_{\mathrm{m}}$ values are much higher than normal plasma HDL apo AI concentrations in the hamster $(\sim 115 \mathrm{mg} / \mathrm{dl})$. In the remaining tissues of the body, HDL apo AI uptake increased linearly with respect to the concentration of HDL apo AI in plasma. The slope of this relationship equals the receptor independent uptake constant $(\mathrm{P})$. The constant $\mathrm{P}$ gives the rate of HDL apo AI uptake (micrograms per hour per gram) via receptor independent (nonsaturable) processes for each $\mathrm{mg} / \mathrm{dl}$ increase in the plasma concentration of HDL apo AI.

The kinetic parameters for HDL cholesteryl ester transport are also shown in Table I. Saturable receptor dependent HDL cholesteryl ester uptake was clearly demonstrated in the adrenal glands and liver with $J^{\mathrm{m}}$ values of $147 \mu \mathrm{g} / \mathrm{h}$ per $\mathrm{g}$ and $58 \mu \mathrm{g} / \mathrm{h}$ per g, respectively. Notably, the $K_{\mathrm{m}}$ values were in the 10-15 $\mathrm{mg} / \mathrm{dl}$ range: far below normal plasma HDL cholesteryl ester concentrations in the hamster $(\sim 60 \mathrm{mg} / \mathrm{dl})$, and far lower (20to 30 -fold) than the $K_{\mathrm{m}}$ values for HDL apo AI in the same tissues. Thus, receptor dependent HDL cholesteryl ester uptake by the liver was saturated at normal plasma HDL concentrations and increased relatively little even with marked elevations in plasma HDL concentrations. With the exception of the adrenal glands, rates of HDL cholesteryl ester uptake in the extrahepatic tissues were quite low (when expressed per gram tissue). The low rates of HDL cholesteryl ester uptake were clearly saturable in most extrahepatic tissues; however, the receptor dependent component was so low that values for $J^{\mathrm{m}}$ and $K_{\mathrm{m}}$ could not be accurately determined for many of these tissues.

Given the unexpected kinetic data for HDL cholesteryl ester transport (that transport was saturated at normal plasma HDL concentrations), we considered the possibility that the

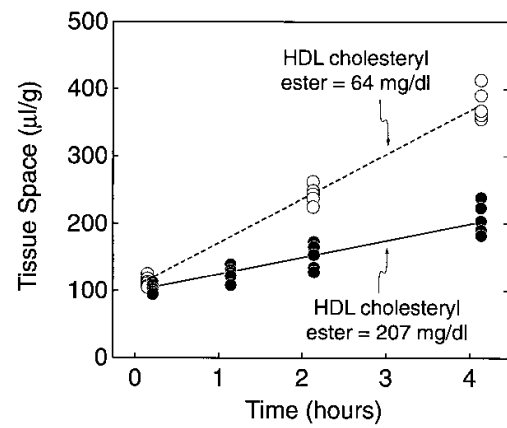

Figure 9. HDL cholesteryl ether accumulation in the liver as a function of time. Animals received primed infusions of $\left[{ }^{3} \mathrm{H}\right]$ cholesteryl oleyl etherlabeled HDL with or without the addition of mass amounts of homologous HDL to raise plasma HDL cholesteryl ester concentrations approximately threefold. The amount of radiolabeled HDL cholesteryl ether present in a tissue is expressed in terms of the plasma volume that would contain the same amount of radiolabeled HDL (Tissue Space). The tissue space of $\left[{ }^{3} \mathrm{H}\right]$ cholesteryl oleyl ether was determined at $10 \mathrm{~min}$, and 1,2, or $4 \mathrm{~h}$ later. The increase in tissue space with time equals the clearance rate in microliters of plasma cleared entirely of radiolabeled HDL per hour per gram of tissue. Each point represents the value from an individual animal.

transport process may have been down-regulated (rather than simply saturated) by the elevated plasma HDL concentrations that were present during the 4 -h infusions. To investigate this possibility, the time-course of HDL cholesteryl ester accumulation over the 4-h experimental period was determined. Animals received primed infusions of tracer HDL cholesteryl ether plus mass amounts of homologous HDL to elevate circulating HDL cholesteryl ester concentrations approximately threefold. Animals were killed at 1, 2, and $4 \mathrm{~h}$. All organs transported HDL cholesteryl ether as a linear function of the time of infusion for at least $4 \mathrm{~h}$ as shown for the liver in Fig. 9. These data suggest that the transport process was not acutely down-regulated by the elevated HDL concentrations that were present during the $4 \mathrm{~h}$ experimental period.

Acton et al. (13) recently identified the scavenger receptor type B1 (SR-BI) as an HDL receptor that could mediate selective HDL cholesteryl ester uptake when transfected into $\mathrm{CHO}$ cells. Originally, this receptor was noted to function as a recep-

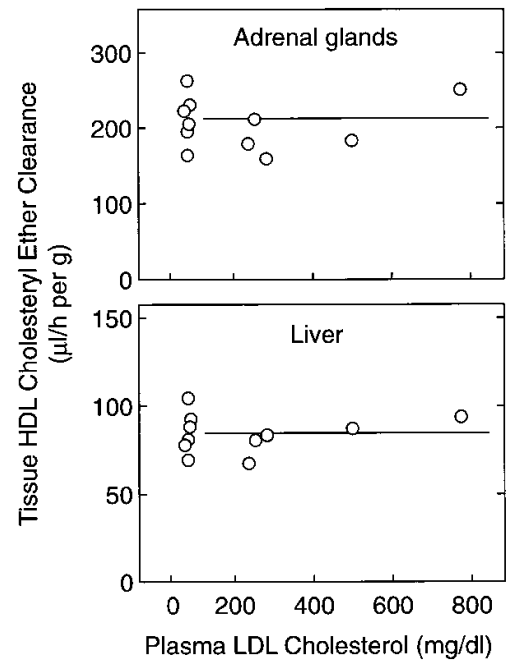

Figure 10. Rates of HDL cholesteryl ether clearance by the adrenal glands and liver as a function of the concentration of LDL in plasma. Rates of HDL cholesteryl ester clearance were quantified in vivo using primed infusions of $\left[{ }^{3} \mathrm{H}\right]$ cholesteryl oleyl ether-labeled HDL. In some animals mass amounts of homologous LDL were added to the trace labeled HDL to abruptly achieve new steady state concentrations of plasma LDL

cholesterol (ranging from 231 to $788 \mathrm{mg} / \mathrm{dl}$ ). Each point represents the value from an individual animal. 
Table II. Rates of Cholesterol Synthesis and Lipoprotein Cholesterol Uptake in the Liver and Extrahepatic Tissues of Normal Hamsters

\begin{tabular}{lcc}
\hline & Liver & Extrahepatic tissues \\
\hline & $\mu g / h$ per 100 body $w t$ & $\mu g / h$ per 100 body $w t$ \\
Cholesterol synthesis & $6 \pm 1$ & $110 \pm 12$ \\
LDL cholesterol uptake & $83 \pm 9$ & $19 \pm 3$ \\
HDL cholesteryl ester uptake & $196 \pm 36$ & $62 \pm 8$ \\
\hline
\end{tabular}

Values represent the mean \pm 1 SD for data obtained in 6 (sterol synthesis and LDL cholesterol uptake) or 12 (HDL cholesteryl ester uptake) animals.

tor for native LDL in COS cells transfected with SR-BI (38). Studies were therefore undertaken to determine if LDL competes with radiolabeled HDL cholesteryl ester for tissue uptake in vivo. In these studies, rates of HDL cholesteryl ether transport were determined in animals in which large mass amounts of unlabeled homologous LDL were added to the primed infusions. As shown in Fig. 10, LDL did not significantly alter the tissue clearance of HDL cholesteryl ether at concentrations of up to 30 times normal.

Under steady state conditions, cholesterol that is acquired by extrahepatic tissues (from lipoproteins or de novo synthesis) must be returned to the liver for excretion, a process that has been termed "reverse cholesterol transport" $(4,5)$. To determine the extent to which the rate of HDL cholesteryl ester uptake by the liver reflects the rate of reverse cholesterol transport, rates of cholesterol acquisition (via de novo synthesis, LDL uptake, HDL uptake) in the extrahepatic tissues were quantified and compared to the rate of HDL cholesteryl ester uptake by the liver. As shown in Table II, the sum of the rates of cholesterol synthesis, LDL cholesterol uptake and HDL cholesteryl ester uptake by all of the extrahepatic tissues (191 $\mu \mathrm{g} / \mathrm{h}$ per $100 \mathrm{~g}$ body weight) closely approximated the rate of HDL cholesteryl ester uptake by the liver $(196 \mu \mathrm{g} / \mathrm{h}$ per $100 \mathrm{~g}$ body weight).

\section{Discussion}

These studies provide the first detailed analysis of the kinetics of HDL apo AI and cholesteryl ester uptake by the various organs of the body in vivo. HDL apo AI and cholesteryl ester transport were studied separately as these components of HDL may enter and leave the particle independently. The metabolism of HDL apo AI and cholesteryl ester differed remarkably in terms of tissue sites of uptake and transport kinetics. When expressed per gram of tissue, the kidney was the most active site of HDL apo AI uptake whereas the adrenal gland was the most active site of HDL cholesteryl ester transport. When expressed per whole organ, the liver was the single most important site of apo AI uptake, but accounted for only $23 \%$ of total HDL apo AI turnover. In contrast, the liver accounted for $76 \%$ of total HDL cholesteryl ester turnover. Thus, at normal HDL concentrations the majority of HDL apo AI $(77 \%)$ was cleared from plasma by extrahepatic tissues whereas the bulk of HDL cholesteryl ester (76\%) was cleared by the liver. These results are consistent with those reported by Glass et al. in the rat $(21,39)$. Importantly, however, the clearance rates for HDL apo AI and cholesteryl ester shown in Figs. 2 and 5 apply only to animals with normal plasma HDL levels. Under conditions in which the concentration of HDL in plasma is raised or lowered, HDL apo AI and cholesteryl ester uptake in each organ will vary depending on the kinetic characteristics of the receptor dependent and receptor independent transport processes in that tissue. To define these kinetic characteristics, the relationship between the concentration of HDL in plasma and the rates of HDL apo AI and cholesteryl ester uptake was determined for all tissues of the hamster using primed infusions of radiolabeled HDL apo AI or cholesteryl ether to which varying mass amounts of unlabeled HDL were added.

Just as there were major differences in the tissue distribution of HDL apo AI and cholesteryl ester transport, there were important differences in the kinetic characteristics of HDL apo AI and cholesteryl ester transport. In the liver and adrenal glands, the $J^{\mathrm{m}}$ values for receptor dependent HDL apo AI and cholesteryl ester transport were similar. In contrast, the $K_{\mathrm{m}}$ values differed greatly for the two moieties of HDL. Halfmaximal rates of HDL cholesteryl ester uptake were achieved at plasma HDL cholesteryl ester concentrations of $10-20 \mathrm{mg} / \mathrm{dl}$ (far below the normal HDL cholesterol ester concentration of $\sim 60 \mathrm{mg} / \mathrm{dl}$ ) whereas half-maximal rates of HDL apo AI uptake were achieved at plasma HDL apo AI concentrations of 300-400 mg/dl (far above the normal HDL apo AI concentration of $\sim 115 \mathrm{mg} / \mathrm{dl}$ ). Thus, HDL cholesteryl ester is taken up via a high affinity (low $K_{\mathrm{m}}$ ) process whereas apo AI is transported via a low affinity (high $K_{\mathrm{m}}$ ) pathway. As a consequence, at normal plasma HDL levels, the clearance of HDL cholesteryl ester exceeds that of HDL apo AI by $\sim 10$-fold in the adrenal glands and by approximately fivefold in the liver. These data suggest that the process of selective cholesteryl ester uptake is related to differences in the affinity of the transport processes involved in particle uptake and selective cholesteryl ester uptake.

Another factor that may contribute to selective uptake in vivo is the transfer of cholesteryl esters from HDL to lower density lipoproteins via the activity of CETP with subsequent uptake of these particles by the liver. However, during infusions of $\left[{ }^{3} \mathrm{H}\right]$ cholesteryl ether-labeled HDL, very little label accumulated in lower density lipoproteins suggesting that the majority of labeled cholesteryl ether that accumulated in tissues was derived directly from HDL. This is consistent with the known low levels of CETP activity in hamster plasma (20, 36) and the less active transfer of cholesteryl ether compared to cholesteryl ester (37).

Limited data have been published regarding the kinetics of HDL transport in vivo. Andersen and Dietschy (40) examined the kinetic characteristics of lipoprotein transport in the rat adrenal gland in vivo. In their studies, the half-maximal transport rate for rat HDL cholesterol was achieved at a plasma HDL cholesterol concentration of $\sim 7 \mathrm{mg} / \mathrm{dl}$, which was far below the plasma HDL cholesterol concentration in the rat. This value is similar to the $K_{\mathrm{m}}$ values for HDL cholesteryl ester transport observed in the current studies and is within the range of values obtained in various cell lines $(39,41)$. In contrast, the apparent $K_{\mathrm{m}}$ for LDL transport in rats and hamsters is $\sim 100 \mathrm{mg} / \mathrm{dl}$ : considerably higher than the normal LDL cholesterol concentration in these species (42) and far higher than values obtained in cultured cells (43). This discrepancy in val- 
ues for LDL receptor affinity between in vivo and in vitro studies has at least two potential explanations. First, under in vivo conditions there may be resistance to the passage of serum lipoproteins into the interstitial space. As a consequence, the concentration of lipoproteins in the pericellular space may be significantly lower than in plasma. In lymph derived from the lower extremity, the concentration of LDL is about onetenth that in plasma, suggesting a significant diffusion barrier to the movement of lipoproteins from plasma to the interstitial fluid of skeletal muscle (44). However, such a diffusion barrier should not exist in the extremely permeable microvascular bed of the liver, where sinusoids offer little, if any, resistance to the passage of lipoproteins. A second possibility for the discrepancy is competition from other lipoproteins for receptor dependent transport. Apo E-containing lipoproteins compete with LDL for uptake via the LDL receptor pathway thereby raising the apparent $K_{\mathrm{m}}$ (lowering the affinity) for receptor dependent LDL transport in vivo (45). The similarity in $K_{\mathrm{m}}$ values for HDL cholesteryl ester transport between in vivo and in vitro studies suggests that lipoproteins other than HDL do not compete for the transport process(es) that mediate(s) HDL cholesteryl ester uptake. This was demonstrated experimentally for LDL in these studies where massive elevations of plasma LDL concentrations failed to significantly alter HDL cholesteryl ester uptake in any organ.

While the liver was the principal site of HDL cholesteryl ester uptake, extrahepatic tissues accounted for $\sim 24 \%$ of total HDL cholesteryl ester turnover in normal animals. In the control hamster, the rate of HDL cholesteryl ester uptake by all extrahepatic tissues combined exceeded the rate of LDL cholesterol uptake in these same tissues by approximately threefold. HDL are thought to play a key role in transporting excess cholesterol from peripheral tissues back to the liver for excretion $(4,5)$. In the most straightforward situation, plasma membrane cholesterol is transferred to nascent discoidal HDL particles within peripheral tissues $(6,7)$. Nascent HDL are converted to mature HDL through the action of $\operatorname{LCAT}(4,5)$. Newly formed cholesteryl esters within the HDL particle are, in turn, transported to the liver, either directly or after transfer to lower density lipoproteins $(5,8)$. Under steady state conditions, the rate of cholesterol acquisition by all of the extrahepatic tissues should equal the rate of HDL cholesteryl ester returned to the liver, ignoring the relatively small amounts of cholesterol that are converted to steroid hormones or lost from the skin. Extrahepatic tissues acquire cholesterol from three sources: (a) de novo synthesis; (b) LDL cholesterol uptake; and (c) HDL cholesterol uptake. In the current studies, the rate of cholesterol synthesis by all of the extrahepatic tissues equaled $110 \mu \mathrm{g} /$ hour per $100 \mathrm{~g}$ body weight. As also demonstrated in these studies, the rate of HDL cholesteryl ester uptake by all of the extrahepatic tissues equaled $62 \mu \mathrm{g} / \mathrm{h}$ per $100 \mathrm{~g}$ body weight. Including the rate of LDL cholesterol uptake by the extrahepatic tissues ( $19 \mu \mathrm{g} / \mathrm{h}$ per $100 \mathrm{~g}$ body weight) yields a value for total cholesterol acquisition by the extrahepatic tissues of $191 \mu \mathrm{g} / \mathrm{h}$ per $100 \mathrm{~g}$ body weight. This value closely approximates the rate of HDL cholesteryl ester uptake by the liver $(196 \mu \mathrm{g} / \mathrm{h}$ per $100 \mathrm{~g}$ body weight). These observations suggest that the rate of HDL cholesteryl ester uptake by the liver accurately reflects the rate of reverse cholesterol transport.

In the kidneys, adrenal glands, and liver, HDL apo AI uptake significantly exceeded albumin uptake and was saturable suggesting a receptor dependent process for apo AI uptake. The nature of this transport process is poorly understood. With the exception of the kidney, HDL apo AI uptake is thought to reflect transport of the whole particle (10). In the kidneys, uptake of HDL apo AI may reflect clearance and degradation of free apo AI in the proximal tubules $(21,27)$. Whether HDL particle uptake and selective cholesteryl ester uptake are mediated by the same or different receptors has not yet been resolved; however, the two processes can be dissociated under a variety of experimental conditions suggesting distinct transport mechanisms (46-48).

Receptor independent transport of HDL apo AI and cholesteryl ester was demonstrated in all tissues. Whereas the liver accounted for the vast majority of receptor dependent HDL cholesteryl ester transport, the bulk of receptor independent HDL transport occurred in extrahepatic tissues. Receptor dependent uptake of HDL cholesteryl ester by the liver is saturated at normal plasma HDL concentrations. Consequently, increases in plasma HDL concentrations will mainly increase the rate of receptor independent (nonsaturable) HDL cholesteryl ester uptake, which occurs predominantly in extrahepatic tissues. Thus, in normal animals, the proportion of plasma HDL cholesteryl ester that is cleared by the liver will fall if plasma HDL concentrations are raised.

Acton and coworkers identified the scavenger receptor type BI (SR-BI) as an HDL receptor that is capable of mediating selective cholesteryl ester uptake in LDL receptor negative CHO cells (13). The exact role of this receptor in mediating HDL cholesteryl ester uptake in vivo is currently unknown. Originally, this receptor was noted to function as a receptor for native LDL in COS cells transfected with SR-BI (38). However, in our studies, LDL did not compete with radiolabeled HDL cholesteryl ether for tissue uptake in vivo. If SR-BI binds LDL (38) and HDL (13), it is somewhat surprising that LDL did not compete with HDL cholesteryl ester for uptake. It is possible that the relatively low concentration of LDL present in control animals is sufficient to completely saturate the receptor; however, it would then be necessary to postulate different binding sites in SR-BI for LDL and HDL. Alternatively, it is possible that receptors other than SR-BI play a significant role in HDL cholesteryl ester transport in vivo. In any event, it is clear that LDL has no detectable effect on HDL cholesteryl ester clearance in any tissue at plasma LDL cholesterol concentrations ranging from 25 to $800 \mathrm{mg} / \mathrm{dl}$.

In summary, these studies establish the kinetic characteristics of HDL apo AI and cholesteryl ester transport in the normal hamster. Perhaps the most notable observation was that HDL cholesteryl ester uptake by the liver, which accounts for the bulk of HDL cholesteryl ester clearance from plasma, is largely saturated at normal HDL concentrations. As a consequence, changes in plasma HDL concentrations are not accompanied by parallel changes in HDL cholesteryl ester delivery to the liver unless the number of transporters or the affinity with which HDL interacts with these transporters is also regulated. These studies also predict that small changes in the rate of cholesteryl ester entering HDL (HDL cholesteryl ester flux) will result in disproportionately large changes in plasma HDL cholesteryl ester concentrations, as removal mechanisms are largely saturated in the normal hamster. Having established the relationship between rates of HDL (apo AI and cholesteryl ester) transport and plasma HDL concentrations in normal animals, it will now be possible to determine the mech- 
anisms whereby dietary and pharmacological factors alter plasma HDL concentrations.

\section{Acknowledgments}

The authors thank Sarah Andrews, Brent Badger, and Jeff Graven for their excellent technical assistance.

This work was supported by grants HL-38049 and HL-47551 from the National Institutes of Health and a grant-in-aid from the American Heart Association-Texas affiliate.

\section{References}

1. Abbott, R.D., P.W.F. Wilson, W.B. Kannel, and W.P. Castelli. 1988. High density lipoprotein cholesterol, total cholesterol screening, and myocardial infarction. The Framingham study. Arteriosclerosis. 8:207-211.

2. Miller, G.J., and N.E. Miller. 1975. Plasma high-density-lipoprotein concentration and development of ischaemic heart disease. Lancet. i:16-19.

3. Gordon, D.J., and B.M. Rifkind. 1989. High-density lipoprotein. The clinical implications of recent studies. N. Engl. J. Med. 321:1311-1316.

4. Glomset, J.A. 1968. The plasma lecithins: cholesterol acyltransferase reaction. J. Lipid Res. 9:155-167.

5. Fielding, C.J., and P.E. Fielding. 1995. Molecular physiology of reverse cholesterol transport. J. Lipid Res. 36:211-228.

6. Fielding, C.J. 1984. The origin and properties of free cholesterol potential gradients in plasma, and their relation to atherogenesis. J. Lipid Res. 25:16241628.

7. Bierman, E.L., and J.F. Oram. 1987. The interaction of high-density lipoproteins with extrahepatic cells. Am. Heart J. 113:549-550.

8. Tall, A.R. 1993. Plasma cholesteryl ester transfer protein. J. Lipid Res. 34:1255-1274

9. Ponsin, G., T. Pulcini, J.T. Sparrow, A.M. Gotto, Jr., and H.J. Pownall. 1993. High density lipoprotein interconversions in rat and man as assessed with a novel nontransferable apolipopeptide. J. Biol. Chem. 268:3114-3119.

10. Khoo, J.C., R.C. Pittman, and E.M. Rubin. 1995. Selective uptake of HDL cholesteryl esters is active in transgenic mice expressing human apolipoprotein A-I. J. Lipid Res. 36:593-600.

11. Pittman, R.C., T.P. Knecht, M.S. Rosenbaum, and C.A. Taylor, Jr. 1987. A nonendocytotic mechanism for the selective uptake of high density lipoprotein-associated cholesterol esters. J. Biol. Chem. 262:2443-2450.

12. Goldberg, D.I., W.F. Beltz, and R.C. Pittman. 1991. Evaluation of pathways for the cellular uptake of high density lipoprotein cholesterol esters in rabbits. J. Clin. Invest. 87:331-346.

13. Acton, S., A. Rigotti, K.T. Landschulz, S. Xu, H.H. Hobbs, and M. Krieger. 1996. Identification of scavenger receptor SR-BI as a high density lipoprotein receptor. Science (Wash. DC). 271:518-520.

14. Quig, D.W., C.M. Arbeeny, and D.B. Zilversmit. 1991. Effects of hyperlipidemias in hamsters on lipid transfer protein activity and unidirectional cholesteryl ester transfer in plasma. Biochim. Biophys. Acta. 1083:257-264.

15. Horton, J.D., J.A. Cuthbert, and D.K. Spady. 1994. Regulation of hepatic $7 \alpha$-hydroxylase expression by dietary psyllium in the hamster. J. Clin. Invest. 93:2084-2092.

16. Schaefer, E.J., R.I. Levy, N.D. Ernst, F.D. Van Sant, and H.B. Brewer, Jr. 1981. The effects of low cholesterol, high polyunsaturated fat, and low fat diets on plasma lipid and lipoprotein cholesterol levels in normal and hypercholesterolemic subjects. Am. J. Clin. Nutr. 34:1758-1763.

17. Zanni, E.E., V.I. Zannis, C.B. Blum, P.N. Herbert, and J.L. Breslow. 1987. Effect of egg cholesterol and dietary fats on plasma lipids, lipoproteins, and apoproteins of normal women consuming natural diets. J. Lipid Res. 28: $518-527$.

18. Woollett, L.A. 1996. Origin of cholesterol in the fetal Golden Syrian hamster: contribution of de novo sterol synthesis and maternal-derived lipoprotein cholesterol. J. Lipid Res. 37:1246-1257.

19. Havel, R.J., H.A. Eder, and J.H. Bragdon. 1955. The distribution and chemical composition of ultracentrifugally separated lipoproteins in human serum. J. Clin. Invest. 34:1345-1353.

20. Goulinet, S., and M.J. Chapman. 1993. Plasma lipoproteins in the Golden Syrian hamster (Mesocricetus auratus): heterogeneity of apoB- and apoA-1-containing particles. J. Lipid Res. 34:943-959.

21. Glass, C.K., R.C. Pittman, G.A. Keller, and D. Steinberg. 1983. Tissue sites of degradation of apoprotein A-I in the rat. J. Biol. Chem. 258:7161-7167.

22. Bilheimer, D.W., S. Eisenberg, and R.I. Levy. 1972. The metabolism of very low density lipoprotein proteins. I. Preliminary in vitro and in vivo observations. Biochim. Biophys. Acta. 260:212-221.
23. Spady, D.K., D.W. Bilheimer, and J.M. Dietschy. 1983. Rates of receptor-dependent and -independent low density lipoprotein uptake in the hamster Proc. Natl. Acad. Sci. USA. 80:3499-3503.

24. Spady, D.K., J.A. Cuthbert, M. Willard, and R.S. Meidell. 1995. Adenovirus-mediated transfer of a gene encoding cholesterol $7 \alpha$-hydroxylase into hamsters increases hepatic enzyme activity and reduces plasma total and low density lipoprotein cholesterol. J. Clin. Invest. 96:700-709.

25. Stein, O., G. Halperin, and Y. Stein. 1980. Biological labeling of very low density lioproteins with cholesteryl linoleyl ether and its fate in the intact rat. Biochim. Biophys. Acta. 620:247-260.

26. Halperin, G., O. Stein, and Y. Stein. 1986. Synthesis of ether analogs of lipoprotein lipids and their biological applications. Methods Enzymol. 129:816-848.

27. Glass, C., R.C. Pittman, D.B. Weinstein, and D. Steinberg. 1983. Dissociation of tissue uptake of cholesterol ester from that of apoprotein A-I of rat plasma high density lipoproteins: selective delivery of cholesterol ester to liver, adrenal and gonad. Proc. Natl. Acad. Sci. USA. 80:5435-5439.

28. Hough, J.L., and D.B. Zilversmit. 1984. Comparison of various methods for in vitro cholesteryl ester labeling of lipoproteins from hypercholesterolemic rabbits. Biochim. Biophys. Acta. 792:338-347.

29. Spady, D.K., and J.M. Dietschy. 1983. Sterol synthesis in vivo in 18 tissues of the squirrel monkey, guinea pig, rabbit, hamster, and rat. J. Lipid Res. 24:303-315.

30. Dietschy, J.M., and D.K. Spady. 1984. Measurement of rates of choleserol synthesis using tritiated water. J. Lipid Res. 25:1469-1476.

31. Jeske, D.J., and J.M. Dietschy. 1980. Regulation of rates of cholesterol synthesis in vivo in the liver and carcass of the rat measured using $\left[{ }^{3} \mathrm{H}\right]$ water. $J$. Lipid Res. 21:364-376.

32. Rifai, N., and M.E. King. 1986. Immunoturbidimetric assays of apolipoproteins A, AI, AII, and B in serum. Clin. Chem. 32:957-961.

33. Brinton, E.A., S. Eisenberg, and J.L. Breslow. 1989. Elevated high density lipoprotein cholesterol levels correlate with decreased apolipoprotein A-I and A-II fractional catabolic rate in women. J. Clin. Invest. 84:262-269.

34. Fitting. 1995. In Ultrafit Manual: Numeric data processing for Apple Macintosh. Biosoft, Cambridge, UK. pg. 7-1-7-12.

35. Shepherd, J., C.J. Packard, A.M. Gotto, Jr., and O.D. Taunton. 1978. A comparison of two methods to investigate the metabolism of human apolipoproteins A-I and A-II. J. Lipid Res. 19:656-661.

36. Stein, Y., Y. Dabach, G. Hollander, and O. Stein. 1990. Cholesteryl ester transfer activity in hamster plasma: increase by fat and cholesterol rich diets. Biochim. Biophys. Acta. 1042:138-141.

37. Green, S.R., W.F. Beltz, D.I. Goldberg, and R.C. Pittman. 1989. Cholesteryl oleyl and linoleyl ethers do not trace their ester counterparts in animals with plasma cholesteryl ester transfer activity. J. Lipid Res. 30:1405-1410.

38. Rigotti, A., S.L. Acton, and M. Krieger. 1995. The class B scavenger receptors SR-BI and CD36 are receptors for anionic phospholipids. J. Biol. Chem. 270:16221-16224.

39. Glass, C., R.C. Pittman, M. Civen, and D. Steinberg. 1985. Uptake of high-density lipoprotein-associated apoprotein A-I and cholesterol esters by 16 tissues of the rat in vivo and by adrenal cells and hepatocytes in vitro. J. Biol. Chem. 260:744-750.

40. Andersen, J.M., and J.M. Dietschy. 1981. Kinetic parameters of the lipoprotein transport systems in the adrenal gland of the rat determined in vivo. Comparison of low and high density lipoproteins of human and rat origin. $J$. Biol. Chem. 256:7362-7370.

41. Rinninger, F., M. Brundert, S. Jackle, P.R. Galle, C. Busch, J.R. Izbicki, X. Rogiers, D. Henne-Bruns, B. Kremer, C.E. Broelsch, and H. Greten. 1994 Selective uptake of high-density lipoprotein-associated cholesteryl esters by human hepatocytes in primary culture. Hepatology. 19:1100-1114.

42. Spady, D.K., J.B. Meddings, and J.M. Dietschy. 1986. Kinetic constants for receptor-dependent and receptor-independent low density lipoprotein transport in the tissues of the rat and hamster. J. Clin. Invest. 77:1474-1481.

43. Goldstein, J.L., and M.S. Brown. 1977. The low-density lipoprotein pathway and its relation to atherosclerosis. Annu. Rev. Biochem. 46:897-930.

44. Sloop, C.H., L. Dory, and P.S. Roheim. 1987. Interstitial fluid lipoproteins. J. Lipid Res. 28:225-237.

45. Woollett, L.A., Y. Osono, J. Herz, and J.M. Dietschy. 1995. Apolipoprotein E competitively inhibits receptor-dependent low density lipoprotein uptake by the liver but has no effect on cholesterol absorption or synthesis in the mouse. Proc. Natl. Acad. Sci. USA. 92:12500-12504.

46. Rinninger, F., and R.C. Pittman. 1987. Regulation of the selective uptake of high density lipoprotein-associated cholesteryl esters. J. Lipid Res. 28 1313-1325.

47. Rinninger, F., and R.C. Pittman. 1988. Regulation of the selective uptake of high density lipoprotein-associated cholesteryl esters by human fibroblasts and Hep G2 hepatoma cells. J. Lipid Res. 29:1179-1194.

48. Rinninger, F., S. Jaeckle, H. Greten, and E. Windler. 1993. Selective association of lipoprotein cholesteryl esters with liver plasma membranes. Biochim. Biophys. Acta. 1166:284-299. 